\title{
Patients' Characteristics Affect the Survival Benefit of Warfarin Treatment for Hemodialysis Patients with Atrial Fibrillation. A Historical Cohort Study
}

\author{
Diego Brancaccio ${ }^{a}$ Luca Neri $^{b}$ Francesco Bellocchio $^{b}$ Carlo Barbieri ${ }^{b}$ \\ Claudia Amato $^{b}$ Flavio Mari $^{b}$ Bernard Canaud $^{c}$ Stefano Stuard ${ }^{c}$ \\ ${ }^{a}$ NephroCare Simone Martini, Milan, and ${ }^{b}$ Fresenius Medical Care, Palazzo Pignano, Italy; ${ }^{c}$ Fresenius Medical Care, Bad \\ Homburg, Germany
}

\section{Key Words}

Warfarin · Atrial fibrillation · Vitamin K inhibitors · End-stage renal disease $\cdot$ Hemodialysis $\cdot$ Renal replacement

therapy · Survival

\begin{abstract}
Background: Stroke prevention in dialysis-dependent patients with atrial fibrillation (AF) is an unresolved clinical dilemma. Indeed, no randomized controlled trial evaluating the efficacy and safety of oral anticoagulants in this population, has been conducted so far. Observational research on the use of warfarin in patients on dialysis has shown conflicting results. This uncertainty is mirrored by the wide variations in warfarin prescription patterns across centers. We sought to evaluate the association between the use of vitamin K antagonists (VKAs) and mortality among hemodialysis patient with $\mathrm{AF}$ and to assess potential factors affecting the risk-benefit profile of warfarin in this population. Methods: A total of 91,987 patients registered in the European Clinical Dialysis Database ${ }^{\circledR}$ system from January 2004 to January 2015. Of which, 9,238 patients were identified with a diagnosis of AF. After excluding ineligible patients, a 1:1 propensity score matched cohort of 1,324 warfarin users and non-users were assembled. Results: VKA use was associated with both increased 90-day survival (hazard ratio, HR 0.47, p < 0.01) and
\end{abstract}

6-year survival (HR 0.76, $\mathrm{p}<0.01)$; however, a trend indicated a stronger early benefit ( $p$ for time-interaction $<0.01$ ). Moderation analysis showed that patients' age and clinical history of stroke strongly influenced warfarin-related benefits on survival. Conclusion: VKA may provide an early survival benefit; however, this is partially offset later during the follow-up. In addition, heterogeneous risk-benefit profiles were observed among subgroups of dialysis-dependent patients with $A F$, further emphasizing the complexities of tailoring stroke prevention strategies in this population.

(c) 2016 S. Karger AG, Basel

\section{Introduction}

Patients with end-stage renal disease (ESRD) on maintenance hemodialysis (HD) face a high risk of atrial fibrillation (AF) [1-7], independent of traditional cardiovascular risk factors [8-10]. Additionally, AF in patients with severe chronic kidney disease has unique pathophysiological features (i.e. cardiac structural alterations, electrolyte imbalance, chronic inflammation, and fluctuating

D.B. and L.N. contributed equally in the preparation of this manuscript.

\section{KARGER}

E-Mail karger@karger.com

www.karger.com/ajn
(C) 2016 S. Karger AG, Basel

0250-8095/16/0444-0258\$39.50/0
Prof. Diego Brancaccio, MD

NephroCare Simone Martini

Via Simone Martini 24, IT-20143 Milano (Italy)

E-Mail diego.brancaccio@fmc-ag-com 
volume overload) [6], and it is associated with an increase in stroke rates and cardiovascular mortality $[6,11]$.

Despite oral anticoagulants being the mainstay of treatment for patients with AF without renal impairment, the use of vitamin K antagonists (VKAs) in ESRD is more controversial, given their unclear effect on stroke and mortality risks $[6,12-23]$, coupled with increased incidence of major bleeding [24]. Concerns with the use of VKAs include initial overdosing due to vitamin $\mathrm{K}$ deficiency in ESRD, heparin use during dialysis, impaired platelet and coagulation function, and the possibility that warfarin may increase calcification formation in ESRD patients [25-29].

Whether reduced thrombus formation is offset by an increased ischemic disease due to vascular aging and major bleeding episodes in HD patients using VKA is a matter of empirical testing. However, the implementation of randomized controlled trials evaluating the long-term efficacy and safety of VKA in HD patients with AF is not realistically foreseeable in the near future.

Current recommendations regarding AF management in HD patients rest on evidence based on observational studies and expert opinion [30-32]. The uncertainty regarding VKA use in this population is mirrored by the heterogeneity of recommendations from various guideline documents and the wide variations of VKA prescription patterns across countries $[6,33]$.

In this study, we sought to evaluate the association between VKA use and mortality in HD patients with AF, and to assess potential factors affecting the risk-benefit profile of warfarin in this population.

\section{Study Population and Methods}

\section{Study Design, Sample, and Setting}

We enrolled all adult patients with a diagnosis of AF treated at 289 European centers belonging to the Fresenius Medical Care network (FME) and registered in the electronic medical records of the European Clinical Dialysis Database $\left(\right.$ EUCLID $\left.^{\circledR}\right)$ clinical database [34] from January 2004 to January 2015. All patients gave consent for using their data anonymously for scientific research. AF was defined by the International Classification of Diseases, 10th Revision, Clinical Modification (ICD-10-CM) codes (I48.XX) recorded in the database by the attending physician or a nurse during a regular physical examination at the dialysis center. To reduce information bias and avoid including patients with a long history of AF before the onset of the observation period, we excluded all patients with AF onset dated more than 90 days earlier than the first HD session registered in EUCLID. We allowed a 90-day grace period between VKA initiation and AF recording to increase the sensitivity of our VKA use classification (online suppl. fig. S1; for all online suppl. material, see www.karger.com/doi/10.1159/000448898). As a registry-based, retrospective study of de-identified data, the study is not subject to the approval of the Ethical Committee, according to Italian regulation.

\section{Definition of Exposure Groups}

We also excluded patients with the first VKA prescription in the first HD session registered in EUCLID to select new users of the drug. Patients with any VKA prescription no earlier than 90 days before the first AF diagnosis were considered VKA users, since we were interested in the mortality risk associated with VKA use in patients with AF. We matched each VKA user with one nonuser based on the date of AF diagnosis, assumption of antiplatelet medication, and propensity score described below.

\section{Socio-Demographic and Clinical Characteristics}

We extracted patients' age, sex, body mass index (BMI), dialysis vintage, albumin, C-reactive protein, phosphate, intact parathyroid hormone, hemoglobin, dialysis parameters (arterial blood pressure and weight pre and post each session), dialysis modality (hemodiafiltration vs. standard HD), and vascular access. Comorbid conditions have been defined as the occurrence of ICD-10-CM codes, suggestive of coronary artery disease, congestive heart failure, peripheral vascular disease (PVD), cerebrovascular disease, dementia, chronic pulmonary disease, connective tissue disorder, peptic ulcer disease, mild liver disease, diabetes without complications, diabetes with organ damage, hemiplegia, tumor without metastasis, moderate or severe liver disease, metastatic solid tumor, and AIDS [34]. Based on comorbidities, the Charlson's Comorbidity Index was calculated [34].

\section{Statistical Analysis}

Propensity Score Matching

Observational studies are increasingly used for comparative effectiveness analysis [35, 36], and propensity score matching allows reducing bias by indication when treatment allocation is not randomized [37]. Propensity scores were generated using logistic regression, predicting VKA use given the observed subject's characteristics. Additionally, to account for changing patterns in VKA prescription and outcomes occurrence rate in the study period, the date of first AF diagnosis in the model was included. To incorporate a proxy of the probability that VKA was prescribed to treat new onset AF, we included in the model the time gap between the date of first VKA prescription and the date of AF diagnosis. We did not include any stroke risk-stratification score (e.g. $\left.\mathrm{CHADS}_{2}\right)$ since it may not accurately characterize HD patients [6]. Conversely, we included individual variables that possibly affect the treatment decision in the statistical model to allow free estimation of their association with treatment choices. To account for variations in clinical characteristics with time, we calculated multiple propensity scores using covariates recorded at each dialysis session. Hence, each patient contributed with as many propensity scores as the number of dialysis sessions received during the study observation period. When a variable included in PS estimation was missing, we used the PS score relative to the dialysis session closest in time. For each VKA patient, all VKA non-users with one or more PS scores calculated at a dialysis session falling within the 30-day window around the date of first VKA prescription were included in the pool of potential matches. A one-to-one exposure matching was performed: each patient in the VKA group was sequentially matched to one patient in the non-treated group who had the same antiplatelet medication status and minimized the propensity score dif- 
ference calculated within 30 days of the first VKA prescription. This procedure allowed balancing relevant time-varying covariates among groups at the time of VKA prescription [38]. We randomly selected one patient among the multiple patients in the non-treated group who satisfied the criterion for matching, to assess the stability of results we replicated the analysis after performing the matching exercise on the pool of unmatched patients ( $n=10$ resampling).

Mortality Associated with VKA Use

To preserve the covariate balance across treatment groups generated by the matching algorithm, all survival analyses were conducted according to an intention-to-treat (ITT) approach. We decided not to perform neither 'as treated' nor 'per protocol' analysis to avoid confounding and selection bias due to informative drug discontinuation. Given that VKA potentially leads to late, irreversible vascular calcification and accelerated cardiovascular aging, long-term effects of VKA persisting after switching would fatally affect any analysis aimed at accounting for drug adherence.

The cumulative incidence of death was calculated using the product-limit method. Mortality risk was calculated as the ratio of events and person-years at risk during the follow-up. Confidence intervals were calculated based on the Poisson distribution.

We used conditional multivariate Cox's proportional hazards analysis to account for the matched design of the study. We censored the last possible record (January 14, 2015) and patient exit from EUCLID (i.e. transplantation, interruption of maintenance HD, exit from network). To minimize survival bias [39], the start date for survival analysis for each pair of matched patients was the onset date of VKA therapy for both groups. The validity of the proportional hazards assumption was tested with time-interactions.

\section{Secondary Analyses}

Given the vascular calcification potential of warfarin, we estimated the interaction between VKA treatment and selected patients' characteristics, thought to influence the propensity for accelerated vascular aging, a condition associated with increased mortality. For this reason, we hypothesized that age, phosphorus baseline concentration, history of cerebrovascular diseases, coronary artery diseases, and peripheral artery diseases might act as moderators of the association between VKA and survival. When the interaction term was statistically significant at $p<0.05$, we estimated the association between VKA use and mortality for each level of the hypothesized moderator to inspect the direction and magnitude of effect modification.

For the same reason, we also evaluated the association between VKA use and either cerebrovascular events or myocardial infarction (see online supplementary Appendix 1 for specific methods, results and commentary).

A p $<0.05$ was considered statistically significant. SAS for Windows version 9.2 (SAS Institute, Cary, N.C., USA) and Matlab were used for all statistical analyses.

\section{Results}

\section{Prevalence of $A F$ and Sample Characteristics}

We identified 9,238 patients with a diagnosis of AF among 91,987 patients registered in the database during the study period. We excluded 5,990 patients with a diagnosis of AF occurring more than 90 days prior to FME admission. The mean follow-up time for the remaining 3,248 patients was 406 days ( $S D$ 483; $\min =3$; $\max =$ 2,808 ) or 3,574 person-years. Sample characteristics before propensity score matching are reported in table 1 .

\section{Propensity Score Matching}

There were 810 patients using VKA among 3,248 patients with AF accounting for $25 \%$ of the sample. Of these, 124 had a VKA prescription for more than 90 days prior to the first diagnosis of $\mathrm{AF}$ and were therefore excluded. Age (OR 0.87 per 10-year change, $\mathrm{p}<0.01$ ), baseline phosphorus levels (OR 1.07, $\mathrm{p}=0.04), \mathrm{BMI}(\mathrm{OR} 1.02$, $\mathrm{p}=0.02)$, and dialysis vintage (OR 1.02, $\mathrm{p}<0.01)$ were associated with VKA prescription. Additionally, there was a gradual increase in VKA prescription rates from 2008 to 2014 (range $24-36 \%$; $\mathrm{p}<0.01$; OR 1.08 per year; $\mathrm{p}<0.01)$. Among the 661 VKA users retained in the study, 4 could not be matched with a non-user due to missing values for variables included in the PS model. In the final sample of VKA users $(n=657), 497(75.6 \%)$ took the medication for at least $80 \%$ of follow-up time. Sample characteristics after propensity score matching are reported in table 1 .

\section{Outcomes Associated with VKA Treatment}

Overall, 472 deaths occurred in the propensity score matched sample (cumulative mortality at 6 years: $72.6 \%$; incidence density: 22.1 events/100 person-years, $95 \%$ CI 20.2-24.2). Among VKA users, 222 died at the end of follow-up (cumulative mortality rate: $17.9,43$, and $69.7 \%$ at 1,3 , and 6 years, respectively; incidence density: 19.3 events/100 person-years, 95\% CI 16.8-21.9). Of which, 102 were taking VKA at the last HD session before death. In the matched VKA non-users, there were 250 deaths at the end of follow-up (cumulative mortality: 23.6, 51.3, and $75.5 \%$ at 1,3 , and 6 years, respectively; incidence density: 21.7 events/ 100 person-years, 95\% CI 19.1-24.6/100; fig. 1). The association of VKA use with reduced mortality was statistically significant at all time-points during follow-up (table 2).

\section{Secondary Analysis}

To identify subgroups of patients with differential VKA-related mortality risk, we tested cross-interactions between VKA use and age ( $\geq 75$ years), phosphorus concentration ( $3.5 \leq \mathrm{p} \leq 5.5 \mathrm{mg} / \mathrm{dl})$, previous history of cerebrovascular disease, coronary artery disease, and peripheral artery disease. Age (interaction term; $\beta_{3}=0.69$, SE 
Table 1. Sample characteristics before and after propensity score matching

\begin{tabular}{|c|c|c|c|c|c|c|c|}
\hline Characteristics & $\begin{array}{l}\text { VKA non-users } \\
(\mathrm{n}=2,438)\end{array}$ & $\begin{array}{l}\text { VKA users } \\
(\mathrm{n}=661)\end{array}$ & $\mathrm{p}$ value & $\begin{array}{l}\text { VKA non-users } \\
(\mathrm{n}=657)\end{array}$ & $\begin{array}{l}\text { VKA users } \\
(\mathrm{n}=657)\end{array}$ & $\mathrm{p}$ value & ES \\
\hline Sex & $1,390(0.57)$ & $397(0.60)$ & 0.11 & $394(0.60)$ & $401(0.61)$ & 0.91 & -0.02 \\
\hline Age & $72.58(10.83)$ & $71.42(9.67)$ & $<0.01$ & $72.4(11.5)$ & $71.9(9.6)$ & 0.38 & -0.05 \\
\hline BMI & $26.71(5.73)$ & $27.34(5.26)$ & $<0.01$ & $26.4(5.5)$ & $27.1(5.3)$ & 0.03 & 0.13 \\
\hline HTN & $390(0.16)$ & $86(0.13)$ & 0.13 & $112(0.17)$ & $92(0.14)$ & 0.29 & 0.13 \\
\hline Glomerulonephritis & $366(0.15)$ & $99(0.15)$ & 0.6 & $92(0.14)$ & $105(0.16)$ & 0.49 & -0.09 \\
\hline Polycystic kidney disease & $122(0.05)$ & $46(0.07)$ & 0.03 & $33(0.05)$ & $46(0.07)$ & 0.16 & -0.19 \\
\hline Interstitial nephritis & $0(0.00)$ & $7(0.01)$ & 0.02 & $33(0.05)$ & $46(0.07)$ & 0.16 & -0.19 \\
\hline Urinary obstruction & $24(0.01)$ & $7(0.01)$ & 1 & & & & \\
\hline Antiplatelet medications & $780(0.32)$ & $178(0.27)$ & $<0.01$ & $184(0.28)$ & $184(0.28)$ & 1.00 & 0.00 \\
\hline Albumin & $3.69(0.5)$ & $3.82(0.43)$ & $<0.01$ & $3.7(0.5)$ & $3.8(0.4)$ & 0.03 & 0.25 \\
\hline CRP & $21.3(30.56)$ & $17.94(31.24)$ & 0.04 & $19.4(26.4)$ & $18.7(30.4)$ & 0.69 & -0.02 \\
\hline PTH & $364.25(361.71)$ & $361.35(323.06)$ & 0.87 & $358.4(393.7)$ & $342.9(315.4)$ & 0.43 & -0.05 \\
\hline Phosphate & $4.47(1.36)$ & $4.58(1.31)$ & 0.06 & $4.4(1.3)$ & $4.5(1.3)$ & 0.16 & 0.08 \\
\hline Hemoglobin & $10.98(1.54)$ & $11.37(1.43)$ & $<0.01$ & & & & \\
\hline Charlson's Comorbidity Index & $6.42(2.17)$ & $6.27(1.98)$ & 0.09 & $6.6(2.3)$ & $6.4(2)$ & 0.10 & -0.10 \\
\hline Cerebrovascular diseases & $390(0.16)$ & $93(0.14)$ & 0.25 & $118(0.18)$ & $112(0.17)$ & 0.77 & 0.03 \\
\hline PVDs & $414(0.17)$ & $106(0.16)$ & 0.66 & $131(0.2)$ & $118(0.18)$ & 0.44 & 0.07 \\
\hline Coronary artery diseases & $219(0.09)$ & $59(0.09)$ & 1 & $66(0.1)$ & $66(0.1)$ & 0.85 & 0.00 \\
\hline Congestive heart failure & $780(0.32)$ & $198(0.3)$ & 0.31 & $230(0.35)$ & $217(0.33)$ & 0.52 & 0.05 \\
\hline Dementia & $24(0.01)$ & $7(0.01)$ & 0.14 & $13(0.02)$ & $7(0.01)$ & 0.08 & 0.35 \\
\hline Connective tissue disorder & $49(0.02)$ & $13(0.02)$ & 0.62 & $7(0.01)$ & $13(0.02)$ & 0.82 & -0.35 \\
\hline Tumor without metastasis & $317(0.13)$ & $73(0.11)$ & 0.23 & $99(0.15)$ & $72(0.11)$ & 0.03 & 0.20 \\
\hline Metastatic solid tumor & $6(0.002)$ & $0(0.00)$ & 0.35 & $0(0)$ & $0(0)$ & 1.00 & - \\
\hline AIDS & $0(0.00)$ & $1(0.00)$ & 0.23 & $0(0)$ & $0(0)$ & 1.00 & - \\
\hline
\end{tabular}

Values are mean $(\mathrm{SD})$ or $\mathrm{n}(\%)$.

$0.31, \mathrm{p}=0.02)$ and previous history of stroke (interaction term; $\beta_{3}=0.91$, SE $0.43, p=0.04$ ) moderated the relationship between VKA use and survival. Hence, we stratified the survival analysis for statistically significant moderators and specified proportional hazard survival models censored at 3 months, 6 months, and at 1 year up to 6 years of follow-up (fig. 2a, b).

\section{Discussion}

The main finding of our study was that patients with AF using warfarin for stroke prevention had a lower mortality compared to patients with no VKA therapy over a 6-year observation period. However, the initial benefit was partially offset during the follow-up. Among 
Fig. 1. Kaplan-Meier curves for survival according to oral anticoagulant therapy during the 6 years of follow-up.

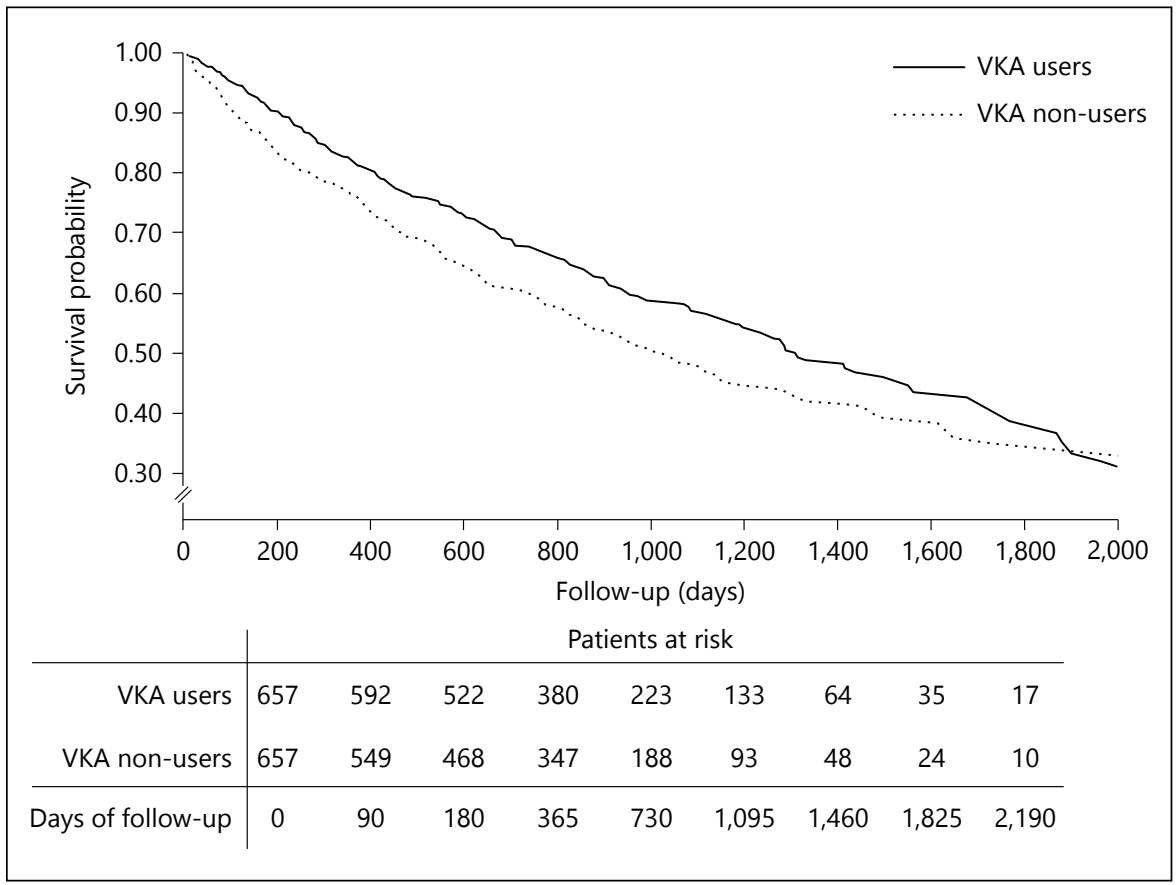

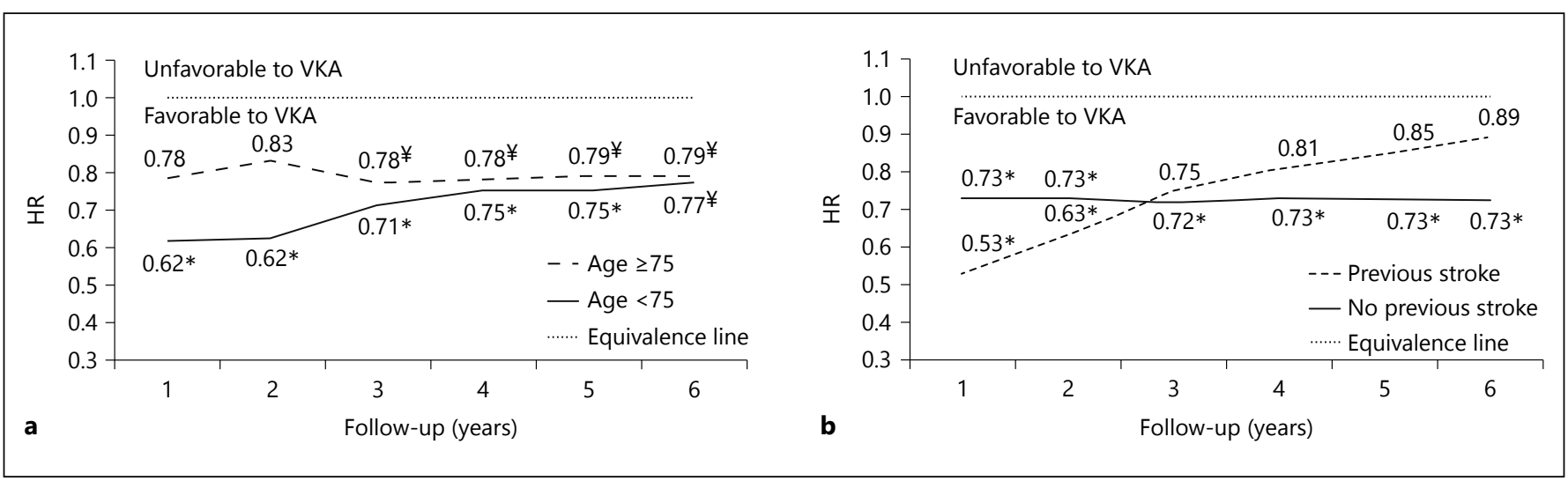

Fig. 2. Mortality risk associated with VKA therapy stratified by age and previous history of stroke. $\mathbf{a}, \mathbf{b} \mathrm{HR}$ represent the relative risk of mortality in patients with oral anticoagulant therapy com- pared to VKA non-users during the 6 years of follow-up. a Effect modification by age. $\mathbf{b}$ Effect modification by previous history of stroke.

Table 2. Mortality in VKA users and non-users

\begin{tabular}{llllr}
\hline Time point/whole sample & HR & p value & \multicolumn{2}{l}{ Events } \\
\cline { 3 - 5 } & & & VKA users & VKA non-users \\
\hline 3 months & & $<0.01$ & 26 & 54 \\
1 year & 0.47 & $<0.01$ & 101 & 135 \\
3 years & 0.69 & $<0.01$ & 187 & 226 \\
6 years & 0.73 & 222 & 250 \\
\hline
\end{tabular}


AF patients without ESRD, warfarin prevents mortality and strongly reduces the risk of stroke [40]. Due to platelet dysfunction, reduced dietary vitamin $\mathrm{K}$ intake, altered bioavailability, higher susceptibility to vascular calcifications, HD patients may have a less favorable riskbenefit profile compared to non-ESRD patients with AF [26-29].

Epidemiological studies seem to corroborate such hypothesis: a recent meta-analysis showed that VKA does not reduce the risk of stroke and increase the risk of bleeding among ESRD patients with AF [24]. The risk-benefit ratio emerging from studies on VKA-related survival are more ambiguous. Several previous studies evaluated mortality risk among AF patients treated with VKA [1517, 20-23, 41-43] (online suppl. fig. 2). Point estimates from 7 previous studies suggest lower mortality [17, 20$23,41-43]$, and 5 of them demonstrated statistically significant reductions in death rate among VKA users [17, $20,21,23,42]$. Consistent with the results, our study showed that the benefits of warfarin therapy might not be offset by an increased risk of fatal side effects in HD patients. On the contrary, one further study found increased mortality among patients on VKA. However, this study did not restrict enrollment of AF patients, and the mean time in therapy for patients on VKA was 50 months, making the results scarcely comparable to the remaining evidence base [44].

Such differences across studies are difficult to reconcile. The risk-benefit profile of warfarin might vary according to patients' characteristics (i.e. age, diabetes, renal impairment, etc.), reflected by different baseline stroke, bleeding, and mortality risk. The mortality rates observed among AF patients in our study was slightly smaller compared to most previous series. Contrary to North-American samples, we found a sizeable proportion of patients with glomerulonephritis-related ESRD and less cases of diabetic nephropathy [14-16]. Hence, subjects enrolled in our study might be somewhat healthier given that diabetic patients more likely have cardiovascular complications and lower survival [45]. However, differences in study design might also play a significant role. Previous studies enrolled incident HD patients $[14-16,23]$ who have higher mortality rates in the first weeks of treatment, screened for eligibility only those hospitalized for a cardiac event [17], and enrolled patients with pre-existing AF $[16,22]$, two potential sources of selection bias.

In our study, the survival benefit for patients treated with VKA was manifested early after therapy initiation, but was progressively lost in the course of follow-up. Al- though this is the first study reporting that VKA relationship with survival is time-dependent, this observation was not unexpected. It has been shown that patients with AF without anticoagulation therapy have a 5-fold risk of 30-day mortality compared to patients receiving VKA after disease onset [46]. Hence, previous studies on HD patients might have overlooked the early benefit of oral anticoagulants because they excluded patients dying within $30-90$ days since the diagnosis of AF $[15,16,20]$. Additionally, patients treated with VKA for prolonged time (greater than 1 year) have a higher risk of vascular calcifications $[44,47]$ and increased arterial stiffness [48], two major risk factors for cardiovascular mortality [49], independent of other well-known risk factors including serum levels of bone markers. Such effects are similar to those observed in patients with vitamin K deficiency [50] and might be particularly strong in HD patients for whom the activity of Matrix $\gamma$-carboxyglutamate proteins, a group of vitamin $\mathrm{K}$-dependent proteins inhibiting vascular mineral deposition, is severely hampered [29, 47, 48]. Our design cannot completely rule out the alternative hypothesis that residual bias by indication affected our risk estimates. Nevertheless, the pattern of association observed in this study is biologically plausible and merits further investigation. If these findings are confirmed by further observational studies and, hopefully, randomized controlled trials assessing the effect of treatment discontinuation schemes, short or medium-term treatment courses with VKA after AF onset might be life-saving among patients with HD.

A further important finding of our study is that the relationship between VKA therapy and survival was moderated by age and previous history of stroke. In one earlier study such components of the CHADS 2 score, but not hypertension and heart failure, were associated with higher stroke risk among HD patients [6]. Our data show that the advantage of warfarin was stronger in patients younger than 75 years of age compared to their older counterparts. However, the extra-benefit for younger patients observed in our study attenuated with time and was not statistically significant after 2 years. While the higher bleeding risk [51] and VKA-related stroke risk [6] might initially penalize elderly patients receiving warfarin compared to younger patients, VKA-related calcification might be accelerated among younger patients [52] and offset the earlier benefits later in the follow-up.

Similarly, we found that patients with previous stroke history, treated with VKA, might have an early survival benefit which is offset during follow-up compared to pa- 
tients without stroke. In this latter group, point estimates were stable and roughly indicated a $30 \%$ reduced mortality risk among VKA users. It is not surprising that the risk-benefit profile of warfarin would be more advantageous for patients with a previous history of stroke, the strongest risk factor for new cerebrovascular events. It is more surprising that such benefit was quickly overcome and lost significance after the second year of follow-up. Given the high prevalence of hypertension and diabetes among patients with previous stroke, such patients might be more susceptible to VKA-related calcification prevailing several months after therapy initiation.

There might be concerns that the statistically significant moderation effects observed in our study were false positive signal, given the multiple interaction terms tested. Subgroup analyses should always be considered as explorative. Nevertheless, for a given sample size, the probability of type II error for moderation analyses (the probability of non-detecting an effect when it truly exists) is higher than in cases of inferences about the main effect. Additionally, the moderation observed in our study was large in magnitude and biologically plausible. Hence, this study provides sufficient evidence to further investigate this important aspect of patient profiling.

This large historical cohort study has several strengths. First, we reduced indication bias by adopting a complex matching strategy. Despite propensity score matching not guaranteeing balancing of unmeasured confounders, the distribution of potentially important confounders was similar across treatment groups. Second, we further reduced confounding by balancing relevant time-varying covariates among groups at the time of VKA prescription by minimizing the propensity score difference calculated at a dialysis session falling within a 30-day window around the date of first VKA prescription. Third, our large sample size allowed us to evaluate the association between VKA use and mortality among patients with different clinical conditions and provided enough statistical power to detect potentially important moderators. Fourth, we reduced survival bias by evaluating the full history of VKA users, thus minimizing the loss of information occurring in previous research artificially truncating the follow-up time. Fifth, we enhanced generalizability by enrolling both incident and prevalent outpatient dialysis patients who better represent the average patient in real-life clinical practice compared to inpatient cohorts or incident dialysis patients.

However, we should acknowledge some limitations. Historical cohort studies are limited by the accuracy of information entered in the electronic chart system. De- spite data related to each HD session being automatically uploaded in the system, comprehensive and accurate reporting on comorbidities and drug prescriptions depends on physicians' and nurses' practice. The very high drug persistence rate observed in our study might be associated with some degree of un-scrutinized carry-over of medication recording beyond the actual use. However, information bias from this source cannot obviously affect the ITT analysis performed in our study. Additionally, we could not discriminate whether VKA was prescribed for prevention of central venous clotting or other conditions possibly associated with warfarin therapy such as PVDs. Hence, we did not exclude these patients. However, the proportion of Central Venous Catheter and PVD was balanced across comparison groups. Hence, confounding from this source is unlikely. However, selection bias might occur. Low dose warfarin is currently contraindicated for prevention of central venous clotting, and doseadjusted prescription may cause serious bleeding without a certain reduction in thrombus formation [53]. Hence, the net benefit in mortality of VKA in patients with AF would be underestimated if our treatment group was erroneously enriched with patients on the drug for central venous clotting prevention. Furthermore, we cannot exclude that transient AF episodes may have gone underdetected or underdiagnosed in our database. Thus, our results may be more generalizable to persistent cases of AF, sufficiently severe to trigger some diagnostic/therapeutic intervention rather than the full cohort of patients with the disease.

The lack of information of VKA use preceding registration in FMC network might be a potential source of bias. Although we sought to select only VKA new users by excluding patients with the first prescription of the drug in the first day in EUCLID, we cannot rule out the possibility that a temporary discontinuation of therapy occurred around that date. Additionally, the prevalence of comorbidities and the incidence of outcomes observed in our study are consistent with previous studies, thus lending support to the validity of our results. Furthermore, even though we balanced observed covariates with propensity score matching, residual confounding due to heterogeneous clinical practices across countries cannot be ruled out in our analysis. Finally, we lack information on international normalized ratio (INR) assessments and percent time in therapeutic INR range. Both these measures are important predictors of antithrombotic efficacy and side effect likelihood and might have provided important clues for the interpretation of our results. 


\section{Conclusions}

Considering the uncertainties regarding stroke phenotype, bleeding risk, and vascular calcification, determining the risk-benefit profile of VKA use in patients with AF undergoing dialysis is extremely complex. It is important to underscore that, in the context of observational research, only consistent evidence provided under different methodological frameworks addressing different sources of bias constitute sufficient evidence base for sensible clinical decision making. Our study contributes to the current debate over VKA use among dialysis patients in several ways. We have found that VKA may provide an early survival benefit, which is partially offset later during follow-up. Even though the development of vascular calcification in VKA users might explain the time-dependency of VKA-related outcomes, our study was not designed to test such hypothesis. Further study should evaluate the complex interplay between reduced thromboembolic events, vascular calcification, and bleeding risk in HD patients. Previous authors have argued that HD population has a different risk-benefit profile for VKA treatment, and extrapolating recommendations from guidelines developed for the general population may pose ESRD patients at high risk of severe complications without clear clinical benefits in terms of reduced stroke or mortality. Our study showed heterogeneous risk-benefit profiles even among subgroups of patients with ESRD patients, further emphasizing the complexities of tailoring stroke prevention strategies in this population.

\section{Acknowledgements}

The study was partially funded by Fresenius Medical Care, Palazzo Pignano (CR), Italy: Dr. Luca Neri received a consultancy fee for medical writing.

\section{Authors' Contribution}

All authors participated in devising the study concept and design; L.N., C.B. and F.B. contributed to statistical analysis planning; F.B. conducted data analysis; all authors provided insights for the interpretation of results; L.N. and D.B. wrote the first version of the manuscript; all authors contributed to manuscript finalization and approved the final version of the manuscript.

\section{Funding}

This research was funded by Fresenius Medical Care, Italy.

\section{Disclosure Statement}

Authors have no conflict of interest to declare.

\section{References}

1 Wiesholzer M, Harm F, Tomasec G, Barbieri G, Putz D, Balcke P: Incidence of stroke among chronic hemodialysis patients with nonrheumatic atrial fibrillation. Am J Nephrol 2001;21:35-39.

2 Vászuez E, Sánchez-Perales C, Borrego F, Garcia-Cortés MJ, Lozano C, Guzmán M, Gil JM, Borrego MJ, Pérez V: Influence of atrial fibrillation on the morbido-mortality of patients on hemodialysis. Am Heart J 2000;140: 886-890.

3 Fabbian F, Catalano C, Lambertini D, Tarroni G, Bordin V, Squerzanti R, Gilli P, Di Landro $\mathrm{D}$, Cavagna R: Clinical characteristics associated to atrial fibrillation in chronic hemodialysis patients. Clin Nephrol 2000;54:234239.

4 Genovesi S, Pogliani D, Faini A, Valsecchi MG, Riva A, Stefani F, Acquistapace I, Stella A, Bonforte G, DeVecchi A, DeCristofaro V, Buccianti G, Vincenti A: Prevalence of atrial fibrillation and associated factors in a population of long-term hemodialysis patients. Am J Kidney Dis 2005;46:897-902.
5 To AC, Yehia M, Collins JF: Atrial fibrillation in haemodialysis patients: do the guidelines for anticoagulation apply? Nephrology (Carlton) $2007 ; 12: 441-447$.

6 Wizemann V, Tong L, Satayathum S, Disney A, Akiba T, Fissell RB, Kerr PG, Young EW, Robinson BM: Atrial fibrillation in hemodialysis patients: clinical features and associations with anticoagulant therapy. Kidney Int 2010;77:1098-1196.

7 Chugh SS, Havmoeller R, Narayanan K, Singh D, Rienstra M, Benjamin EJ, Gillum RF, Kim YH, McAnulty JH Jr, Zheng ZJ, Forouzanfar MH, Naghavi M, Mensah GA, Ezzati M, Murray CJ: Worldwide epidemiology of atrial fibrillation: a global burden of disease 2010 study. Circulation 2014;129:837-847.

8 Alonso A, Lopez FL, Matsushita K, Loehr LR, Agarwal SK, Chen LY, Soliman EZ, Astor BC, Coresh J: Chronic kidney disease is associated with the incidence of atrial fibrillation: the atherosclerosis risk in communities (ARIC) study. Circulation 2011;123:29462953.
9 Baber U, Howard VJ, Halperin JL, Soliman EZ, Zhang X, McClellan W, Warnock DG, Muntner P: Association of chronic kidney disease with atrial fibrillation among adults in the united states: reasons for geographic and racial differences in stroke (REGARDS) study. Circ Arrhythm Electrophysiol 2011;4: 26-32.

10 Horio T, Iwashima Y, Kamide K, Tokudome T, Yoshihara F, Nakamura S, Kawano Y: Chronic kidney disease as an independent risk factor for new-onset atrial fibrillation in hypertensive patients. J Hypertens 2010;28:1738-1744.

11 Zimmerman D, Sood MM, Rigatto C, Holden RM, Hiremath S, Clase CM: Systematic review and meta-analysis of incidence, prevalence and outcomes of atrial fibrillation in patients on dialysis. Nephrol Dial Transplant 2012;27:3816-3822.

12 Winkelmayer WC, Liu J, Patrick AR, Setoguchi S, Choudhry NK: Prevalence of atrial fibrillation and warfarin use in older patients receiving hemodialysis. J Nephrol 2012;25: 341-353. 
13 Olesen JB, Lip GY, Kamper AL, Hommel K, Køber L, Lane DA, Lindhardsen J, Gislason GH, Torp-Pedersen C: Stroke and bleeding in atrial fibrillation with chronic kidney disease. N Engl J Med 2012;367:625-635.

14 Shah M, Avgil Tsadok M, Jackevicius CA, Essebag V, Eisenberg MJ, Rahme E, Humphries $\mathrm{KH}$, Tu JV, Behlouli H, Guo H, Pilote L: Warfarin use and the risk for stroke and bleeding in patients with atrial fibrillation undergoing dialysis. Circulation 2014;129: 1196-1203.

15 Winkelmayer WC, Liu J, Setoguchi S, Choudhry NK: Effectiveness and safety of warfarin initiation in older hemodialysis patients with incident atrial fibrillation. Clin J Am Soc Nephrol 2011;6:2662-2668.

16 Chan KE, Lazarus JM, Thadhani R, Hakim RM: Warfarin use associates with increased risk for stroke in hemodialysis patients with atrial fibrillation. J Am Soc Nephrol 2009;20: 2223-2233.

17 Carrero JJ, Evans M, Szummer K, Spaak J, Lindhagen L, Edfors R, Stenvinkel P, Jacobson SH, Jernberg T: Warfarin, kidney dysfunction, and outcomes following acute myocardial infarction in patients with atrial fibrillation. JAMA 2014;311:919-928.

18 To AC, Yehia M, Collins JF: Atrial fibrillation in haemodialysis patients: do the guidelines for anticoagulation apply? Nephrology (Carlton) 2007;12:441-447.

19 Genovesi S, Vincenti A, Rossi E, Pogliani D, Acquistapace I, Stella A, Valsecchi MG: Atrial fibrillation and morbidity and mortality in a cohort of long-term hemodialysis patients. Am J Kidney Dis 2008;51: 255-262.

20 Shen JI, Montez-Rath ME, Lenihan CR, Turakhia MP, Chang TI, Winkelmayer WC: Outcomes after warfarin initiation in a cohort of hemodialysis patients with newly diagnosed atrial fibrillation. Am J Kidney Dis 2015;66: 677-688.

21 Bonde AN, Lip GY, Kamper AL, Hansen PR, Lamberts M, Hommel K, Hansen ML, Gislason GH, Torp-Pedersen C, Olesen JB: Net clinical benefit of antithrombotic therapy in patients with atrial fibrillation and chronic kidney disease: a nationwide observational cohort study. J Am Coll Cardiol 2014;64: 2471-2482.

22 Genovesi S, Rossi E, Gallieni M, Stella A, Badiali F, Conte F, Pasquali S, Bertoli S, Ondei P, Bonforte G, Pozzi C, Rebora P, Valsecchi MG, Santoro A: Warfarin use, mortality, bleeding and stroke in haemodialysis patients with atrial fibrillation. Nephrol Dial Transplant 2015;30:491-498.

23 Abbott KC, Trespalacios FC, Taylor AJ, Agodoa LY: Atrial fibrillation in chronic dialysis patients in the United States: risk factors for hospitalization and mortality. BMC Nephrol 2003;4:1.

$24 \mathrm{Li} \mathrm{J}$, Wang L, Hu J, Xu G: Warfarin use and the risks of stroke and bleeding in hemodialysis patients with atrial fibrillation: a system- atic review and a meta-analysis. Nutr Metab Cardiovasc Dis 2015;25:706-713.

25 Palaniswamy C, Sekhri A, Aronow WS, Kalra A, Peterson SJ: Association of warfarin use with valvular and vascular calcification: a review. Clin Cardiol 2011;34:74-81.

26 Danziger J: Vitamin K-dependent proteins, warfarin, and vascular calcification. Clin J Am Soc Nephrol 2008;3:1504-1510.

27 Yang F, Chou D, Schweitzer P, Hanon S: Warfarin in haemodialysis patients with atrial fibrillation: what benefit? Europace 2010;12: 1666-1672.

28 Limdi NA, Limdi MA, Cavallari L, Anderson AM, Crowley MR, Baird MF, Allon M, Beasley TM: Warfarin dosing in patients with impaired kidney function. Am J Kidney Dis 2010;56:823-831.

29 Cranenburg EC, Schurgers LJ, Uiterwijk HH, Beulens JW, Dalmeijer GW, Westerhuis R, Magdeleyns EJ, Herfs M, Vermeer C, Laverman GD: Vitamin K intake and status are low in hemodialysis patients. Kidney Int 2012;82: 605-610.

30 Marinigh R, Lane DA, Lip GY: Severe renal impairment and stroke prevention in atrial fibrillation: implications for thromboprophylaxis and bleeding risk. J Am Coll Cardiol 2011;57:1339-1348.

31 January CT, Wann LS, Alpert JS, Calkins H, Cigarroa JE, Cleveland JC Jr, Conti JB, Ellinor PT, Ezekowitz MD, Field ME, Murray KT, Sacco RL, Stevenson WG, Tchou PJ, Tracy CM, Yancy CW: 2014 AHA/ACC/HRS guideline for the management of patients with atrial fibrillation: a report of the American college of cardiology/American heart association task force on practice guidelines and the heart rhythm society. J Am Coll Cardiol 2014;130:e199-e267.

32 Camm AJ, Lip GY, De Caterina R, Savelieva I, Atar D, Hohnloser SH, Hindricks G, Kirchhof $\mathrm{P}$; ESC Committee for Practice Guidelines (CPG): 2012 focused update of the ESC guidelines for the management of atrial fibrillation: an update of the 2010 ESC guidelines for the management of atrial fibrillation. Developed with the special contribution of the European heart rhythm association. Eur Heart J 2012;33:2719-2747.

33 Steil H, Amato C, Carioni C, Kirchgessner J, Marcelli D, Mitteregger A, Moscardo V, Orlandini G, Gatti E: EuCliD - a medical registry. Methods Inf Med 2004;43:83-88.

34 Sundararajan V, Henderson T, Perry C, Muggivan $\mathrm{A}$, Quan $\mathrm{H}$, Ghali WA: New ICD-10 version of the Charlson comorbidity index predicted in-hospital mortality. J Clin Epidemiol 2004;57:1288-1294.

35 Fleurence RL, Naci H, Jansen JP: The critical role of observational evidence in comparative effectiveness research. Health Aff (Millwood) 2010;29:1826-1833.

36 Austin PC: An introduction to propensity score methods for reducing the effects of confounding in observational studies. Multivariate Behav Res 2011;46:399-424.
37 Lu B: Propensity score matching with timedependent covariates. Biometrics 2005;61: 721-728.

38 Lévesque LE, Hanley JA, Kezouh A, Suissa S: Problem of immortal time bias in cohort studies: example using statins for preventing progression of diabetes. BMJ 2010;340: b5087.

39 Sood MM, Larkina M, Thumma JR, Tentori F, Gillespie BW, Fukuhara S, Mendelssohn DC, Chan K, de Sequera P, Komenda P, Rigatto $\mathrm{C}$, Robinson BM: Major bleeding events and risk stratification of antithrombotic agents in hemodialysis: results from the DOPPS. Kidney Int 2013;84:600-608.

40 Agarwal S, Hachamovitch R, Menon V: Current trial-associated outcomes with warfarin in prevention of stroke in patients with nonvalvular atrial fibrillation: a meta-analysis. Arch Intern Med 2012;172:623-631.

41 Lenihan CR, Montez-Rath ME, Shen JI, Scandling JD, Turakhia MP, Chang TI, Winkelmayer WC: Correlates and outcomes of warfarin initiation in kidney transplant recipients newly diagnosed with atrial fibrillation. Nephrol Dial Transplant 2015;30:321329.

42 Friberg L, Benson L, Lip GY: Balancing stroke and bleeding risks in patients with atrial fibrillation and renal failure: the Swedish atrial fibrillation cohort study. Eur Heart J 2015;36: 297-306

43 Wang TK, Sathananthan J, Marshall M, Kerr A, Hood C: Relationships between anticoagulation, risk scores and adverse outcomes in dialysis patients with atrial fibrillation. Heart Lung Circ 2016;25:243-249.

44 Fusaro M, Tripepi G, Noale M, Plebani M, Zaninotto M, Piccoli A, et al: Prevalence of vertebral fractures, vascular calcifications, and mortality in warfarin treated hemodialysis patients. Curr Vasc Pharmacol 2015;13:248258

45 Ramirez SP, McCullough KP, Thumma JR, Nelson RG, Morgenstern H, Gillespie BW, Inaba $\mathrm{M}$, Jacobson $\mathrm{SH}$, Vanholder R, Pisoni RL, Port FK, Robinson BM: Hemoglobin $\mathrm{A}(1 \mathrm{c})$ levels and mortality in the diabetic hemodialysis population: findings from the dialysis outcomes and practice patterns study (DOPPS). Diabetes Care 2012;35:25272532.

46 Hylek EM, Go AS, Chang Y, Jensvold NG, Henault LE, Selby JV, Singer DE: Effect of intensity of oral anticoagulation on stroke severity and mortality in atrial fibrillation. $\mathrm{N}$ Engl J Med 2003;349:1019-1026.

47 Holden RM, Sanfilippo AS, Hopman WM, Zimmerman D, Garland JS, Morton AR: Warfarin and aortic valve calcification in hemodialysis patients. J Nephrol 2007;20:417422

48 Mac-Way F, Poulin A, Utescu MS, et al: The impact of warfarin on the rate of progression of aortic stiffness in hemodialysis patients: a longitudinal study. Nephrol Dial Transplant 2014;29:2113-2120. 
49 Sigrist MK, Taal MW, Bungay P, McIntyre CW: Progressive vascular calcification over 2 years is associated with arterial stiffening and increased mortality in patients with stages 4 and 5 chronic kidney disease. Clin J Am Soc Nephrol 2007;2:1241-1248.

50 Fusaro M, Noale M, Viola V, Galli F, Tripepi $\mathrm{G}$, Vajente N, et al: Vitamin K, vertebral fractures, vascular calcifications, and mortality: vitamin K Italian (VIKI) dialysis study. J Bone Miner Res 2012;27:2271-2278.
51 Eikelboom JW, Wallentin L, Connolly SJ, Ezekowitz M, Healey JS, Oldgren J, Yang S, Alings M, Kaatz S, Hohnloser SH, Diener HC, Franzosi MG, Huber K, Reilly P, Varrone J, Yusuf S: Risk of bleeding with 2 doses of dabigatran compared with warfarin in older and younger patients with atrial fibrillation: an analysis of the randomized evaluation of long-term anticoagulant therapy (RE-LY) trial. Circulation 2011;123:2363-2372.
52 Tantisattamo E, Han KH, O'Neill WC: Increased vascular calcification in patients receiving warfarin. Arterioscler Thromb Vasc Biol 2015;35:237-242.

53 Bishop L, Dougherty L, Bodenham A, Mansi J, Crowe P, Kibbler C, Shannon M, Treleaven J: Guidelines on the insertion and management of central venous access devices in adults. Int J Lab Hematol 2007;29:261278 